\title{
Pengaruh Profitabilitas dan Corporate Governance Terhadap Tax Avoidance Pada Perusahaan BUMN Yang Terdaftar Di Bursa Efek Indonesia Periode 2014-2018
}

\author{
Indra Sulistiana ${ }^{1}$, Saeful Fachri ${ }^{2}$, Muhammad Saefi Mubarok ${ }^{3}$ \\ ${ }^{1,2,3}$ Program StudiAkuntansiSekolah Tinggi Ilmu Ekonomi Banten \\ *Email korespondensi: fachri@stiebanten.ac.id
}

\begin{abstract}
Tax collection in Indonesia is still experiencing many obstacles, as a result, the effectiveness of tax collection has continued to decline from 2012 to 2015 with an average of 3.74\%. This study has the aim of knowing the factors that influence Tax Avoidance. The research method used is descriptive method with a quantitative approach. The $t$-test results show that the profitability variable has a significant level of 0.414 greater than 0.05 with a t-statistic of -0.882 and a t-table of 1.992, which means the t-count is smaller than the t-table. Furthermore, the results show that the independent commissioner variable has a t-count value that is smaller than the t-table value (-3.211 $<1.992)$ and a significance level that is less than $0.05(0.002<0.05)$. Then, the audit quality variable has a $t$ count value that is smaller than the t-table value $(-0.977<1.992)$ and a significance level greater than 0.05 $(0.332>0.05)$. Based on the results of the t test above, it can be concluded that the profitability variable has no significant effect on Tax Avoidance. Furthermore, the independent commissioner variable (Inboard) has significant effect on Tax Avoidance. Partially, the audit quality variable has no significant effect on Tax Avoidance.
\end{abstract}

Keywords: Profitability, Independent Commissioner, Audit Quality, Tax Avoidance, Corporate Governance

Saran sitasi: Sulitiana, I., Fachri, S., \& Mubarok, M. S. (2021). Pengaruh Profitabilitas dan Corporate Governance Terhadap Tax Avoidance Pada Perusahaan BUMN Yang Terdaftar Di Bursa Efek Indonesia Periode 2014-2018. Jurnal Akuntansi dan Pajak, 21 (2), 333-339. doi:http://dx.doi.org/10.29040/jap.v21i2.1561

DOI: http://dx.doi.org/10.29040/jap.v21i2.1561

\section{PENDAHULUAN}

Pajak merupakan sumber pendapatan bagi negara, sedangkan bagi perusahaan, pajak adalah beban yang akan mengurangi keuntungan atau laba bersih. Perbedaaan kepentingan dari fiskus yang menginginkan penerimaan pajak yang besar dan kontinyu tentu bertolak belakang dengan kepentingan dari perusahaan, yang menginginkan pembayaran pajak seminimal mungkin.

Perbedaan kepentingan tersebut menyebabkan optimalisasi pemungutan pajak di Indonesia masih banyak mengalami kendala akibatnya efektivitas pemungutan pajak terus mengalami penurunan dari tahun 2012 hingga 2015 dengan rata rata mencapai 3,74\% (fiskal.kemenkeu.go.id, 2015). Peristiwa tersebut menjelaskan bahwa penerimaan dari sektor pajak yang seharusnya diterima oleh negara tidak sebesar pembayaran yang dilakukan oleh wajib pajak. Salah satu faktor yang menyebabkan terhambatnya penerimaan pajak adalah penghindaran pajak atau Tax
Avoidance, yaitu proses pengendalian tindakan agar terhindar dari konsekuensi pengenaan pajak yang tidak dikehendaki, dalam hal ini sama sekali tidak ada suatu pelanggaran hukum yang dilakukan.

Penghindaran pajak dilakukan perusahaan karena pengaruh laba. Tujuan perusahaan akan tercapai bila mampu mensejahterakan para pemegang saham, meningkatkan kekayaan pemilik perusahaan dengan cara mencapai keuntungan yang maksimal atau perolehan laba yang paling optimal (Minanari, 2018). Pajak merupakan hal yang menjadi perhatian penting karena beban pajak akan mengurangi laba bersih dan sudah menjadi rahasia umum perusahaan menginginkan pembayaran pajak seminimal mungkin (Sari, 2014).

Penelitian mengenai pengaruh profitabilitas terhadap Tax Avoidance, telah dilakukan di Indonesia diantaranya sebagai berikut. ROA berpengaruh pada penghindaran pajak pada perusahaan yang terdaftar di BEI dan masuk peringkat CGPI periode 2010- 
2012 (Darmawan \& Sukartha, 2014). Tetapi, terdapat research gap dalam penelitian ini yang menyatakan bahwa ROA tidak berpengaruh terhadap Tax Avoidance. ROA tidak berpengaruh terhadap Tax Avoidance pada perusahaan yang terdaftar di JII tahun 2011-2015 (Ismi \& Linda, 2016). Berdasarkan teori dan kajian penelitian terdahulu, peneliti merumuskan masalah penelitian apakah Profitabilitas (ROA) berpengaruh signifikan terhadap Tax Avoidance Pada Perusahaan BUMN yang Terdaftar di Bursa Efek Indonesia (2014-2018)?

Faktor lain yang diduga mempengaruhi Tax Avoidance adalah Corporate Governance. Perusahaan yang memiliki mekanisme Corporate Governance yang baik maka akan berbanding lurus dengan kepatuhan perusahaan dalam memenuhi kewajiban pajaknya (Sartori, 2011). Banyaknya perusahaan yang melakukan perilaku Tax Avoidance membuktikan bahwa Corporate Governance belum sepenuhnya dilakukan dengan baik oleh perusahaan-perusahaan publik di Indonesia. Dalam penelitian ini, Indikator yang digunakan untuk menilai kinerja Corporate Governance adalah faktor komisaris independen dan kualitas audit.

Penelitian mengenai pengaruh Corporate Governance (Komisaris Independen) terhadap Tax Avoidance, telah dilakukan di Indonesia diantaranya sebagai berikut. Berdasarkan pengujian hipotesis bahwa variabel Komisaris Independen berpengaruh terhadap penghindaran pajak (Tax Avoidance) Studi Empiris Pada Sektor Industri Barang Konsumsi yang terdaftar di Bursa Efek Indonesia Periode 2010-2014 (Eksandy, 2017). Selanjutnya, Dewan Komisaris Independen berpengaruh positif terhadap Tax Avoidance pada perusahaan perbankan yang terdaftar di BEI periode 2012 - 2016 (Dewi, 2019). Berdasarkan teori dan kajian penelitian terdahulu, peneliti merumuskan masalah penelitian apakah Komisaris Independen berpengaruh signifikan terhadap Tax Avoidance Pada Perusahaan Bumn yang Terdaftar di Bursa Efek Indonesia (2014-2018)?

Selanjutnya variabelCorporate Governance yang diduga berpengaruh terhadap Tax Avoidance adalah Kualitas Audit. Penelitian terdahulu yang mengkaji pengaruh Kualitas Audit terhadap Tax Avoidance adalah sebagai berikut. Berdasarkan hasil pengujian secara parsial Kualitas Auditterhadap Tax Avoidance diperoleh hasil bahwa Kualitas Audit memiliki pengaruh signifikan negatif terhadap Tax Avoidance perusahaan makanan dan minuman yang terdaftar di Bursa Efek Indonesia periode 2011-2015 (Khairunisa et al., 2017). Penelitian lain memiliki hasil penelitian bahwa Kualitas Audit tidak berpengaruh terhadap Tax Avoidance(Damayanti \& Susanto, 2016). Berdasarkan teori dan kajian penelitian terdahulu, selanjutnya peneliti merumuskan masalah penelitian apakah Kualitas Audit berpengaruh signifikan terhadap Tax Avoidance Pada Perusahaan BUMN yang Terdaftar di Bursa Efek Indonesia (2014-2018)?.

Kemudian secara simultan, peneliti membuat rumusan masalah apakah profitabilitas (ROA) dan Corporate Governance (Komisaris Independen dan Kualitas Audit) berpengaruh signifikan terhadap Tax Avoidancepada Perusahaan BUMN yang Terdaftar di Bursa Efek Indonesia (2014-2018)?

Melihat dari penelitian sebelumnya dan latar belakang masalah penulis akan melakukan penelitian yang memiliki perbedaaan dengan penelitian sebelumnya Corporate Governance yang digunakan sebagai variabel yaitu Komisaris Independen, dan Kualitas Audit, Maka dari itu penulis kali ini akan melakukan penelitian dengan judul "Pengaruh Profitabilitas dan Corporate Governance Terhadap Tax Avoidance Pada Perusahaan BUMN Yang Terdaftar Di Bursa Efek Indonesia 2014 - 2018”.

\section{METODE PENELITIAN}

Metode penelitian yang digunakan metode kuantitatif sedangkan pendekatan penelitian yang digunakan adalah statistik deskriptif. Dalam penelitian ini populasi yang digunakan adalah dokumen laporan keuangan perusahan BUMN yang terdaftar di Bursa Efek Indonesia. Teknik pengambilan sampel dilakukan secara purposive sampling atau pengambilan sampel dengan cara menetapkan ciri-ciri khusus (kriteria). Adapaun kriteria sampel penelitian yaitu: (1) Perusahaan BUMN dari tahun 2014-2018, dan (2) Perusahaan yang tidak memiliki nilai minus untuk keperluan analisa. Berdasarkan kriteria yang ditetapkan diperoleh total keseluruhan sampel (5 tahun $\mathrm{x} 16$ perusahaan) atau 80 sampel penelitian.

Teknik pengumpulan data yang digunakan yaitu dokumentasi dengan meliha tlaporan tahunan yang di terbitkan oleh perusahaan manufaktur dar itahun 2014 sampai 2018 di Bursa Efek Indonesia (BEI), analisis data bersifat kuantitatif/statistik dengan tujuan untuk menguji hipotesis. penelitian ini akan menjelaskan pengaruh antar variabel-variabel yang akan diteliti, yaitu pengaruh variabel profitabilitas dan variabel Corporate Governance Terhadap Tax Avoidance. 


\section{HASIL DAN PEMBAHASAN}

\subsection{Hasil penelitian}

\section{Analisis Statistik Deskriptif}

.Hasil analisis deskriptif dengan menggunakan SPSS dari variabel-variabel penelitian adalah sebagai berikut:

Tabel 1.Hasil Uji Statistik Deskriptif

\begin{tabular}{crcccr}
\hline & $\mathrm{N}$ & Min & Max & Mean & Std. Dev \\
\hline ROA & 80 & 0,009 & 0,226 & 0,05966 & 0,046576 \\
INDBOARD & 80 & 0,200 & 1.000 & 0,45981 & 0,140278 \\
KAP & 80 & 0 & 1 & 0,60 & 0,493 \\
TA & 80 & 0,050 & 3,822 & 0,36343 & 0,559846
\end{tabular}
Valid N

(listwise) 80

Berdasarkan hasil perhitungan statistik deskriptif diketahui bahwa Tax Avoidance dalam penelitian ini diukur dari beban pajak dibagi dengan laba sebelum pajak. Hasil uji statistik deskriptif menunjukkan bahwa variabel Tax Avoidance memiliki nilai minimum sebesar 0,050 dengan nilai maksimum sebesar 3,822. Dimana nilai mimimum itu dimiliki oleh PT. Wijaya Karya (PERSERO) Tbk. padatahun 2014 dan nilai maksimum dimiliki oleh PT. Waskita Karya (PERSERO) Tbk. pada tahun 2015. Nilai ratarata Tax Avoidance sebesar 0,363 dengan standar deviasi sebesar 0.559 .

Variabel independen pertama pada penelitian ini yaitu Profitabilitas (X1) dalam penelitian ini diindikatorkan oleh nilai ROA yang diukur dari Laba Bersih dibagi Total Asset. Hasil uji statistik deskriptif menunjukkan bahwa variabel Profitabilitas memiliki nilai minimum sebesar 0,009 dengan nilai maksimum sebesar 0,226. Dimana nilai minimum itu dimiliki oleh PT. Semen Baturaja (PERSERO) Tbk. Pada tahun 2014 dan nilai maksimum dimiliki oleh PT. Bukit Asam (PERSERO) Tbk. pada tahun 2018. Nilai rata-rata Profitabilitas sebesar 0,059 dengan standar deviasi sebesar 0,046.

Variabel independen kedua pada penelitian ini yaitu Komisaris Independen (X2) dalam penelitian ini diukur dari jumlah anggota Komisaris Independen dibagi dengan jumlah Dewan Komisaris. Hasil uji statistik deskriptif menunjukkan bahwa variabel Komisaris Independen memiliki nilai minimum sebesar 0,20 dengan nilai maksimum sebesar 1,00. Dimana nilai minimum itu dimiliki oleh PT. PP (PERSERO)Tbk. pada tahun 2017 dan 2018 dan nilai maksimum dimiliki oleh PT. Perusahaan Gas Negara Tbk. pada tahun 2018. Nilai rata-rata Komisaris Independen sebesar 0,459 dengan standar deviasi sebesar 0,140 .
Variabel independen ketiga pada penelitian ini yaitu Kualitas Audit (X3) diukur dengan variable dummy apabila perusahaan di audit oleh KAP BIG 4 maka diberi nilai 1 dan diberi nilai 0 apabila perusahaan di audit oleh auditor non BIG4. Hasil uji statistik deskriptif menunjukkan bahwa variabel Kualitas Audit memiliki nilai minimum sebesar 0 dengan nilai maksimum sebesar 1,00.Nilai rata-rata Kualitas Audit sebesar 0,60 dengan standar deviasi sebesar 0,493. Hal ini menunjukkan bahwa perusahaan yang di audit oleh KAP Big 4 yaitu sebanyak $60 \%$, sedangkan sisanya $40 \%$ di audit oleh KAP Non Big 4, hal ini menandakan bahwa pangsa pasar KAP Big 4 di Indonesia mendominasi perikatan audit.

\section{Uji Asumsi Klasik}

\section{a. Uji Normalitas}

Berdasarkan hasil analisis data yang diperoleh tidak berdistribusi normal, sehingga terdapat data outlier (tidak digunakan atau dikeluarkan dari sampel).Setelah diketahui data outlier tersebut maka jumlah sampel yang sebelumnya adalah 80 (delapan puluh) menjadi sebanyak 69 (enam puluh Sembilan). Pengujian normalitas dalam penelitian menggunakan One-Sample Kolmogorov-Smirnov Test. Hasil pengujian penelitian ini terlihat pada tabel berikut:

Tabel 2.HasilUjiNormalitas

\section{One-Sample Kolmogorov-Smirnov Test}

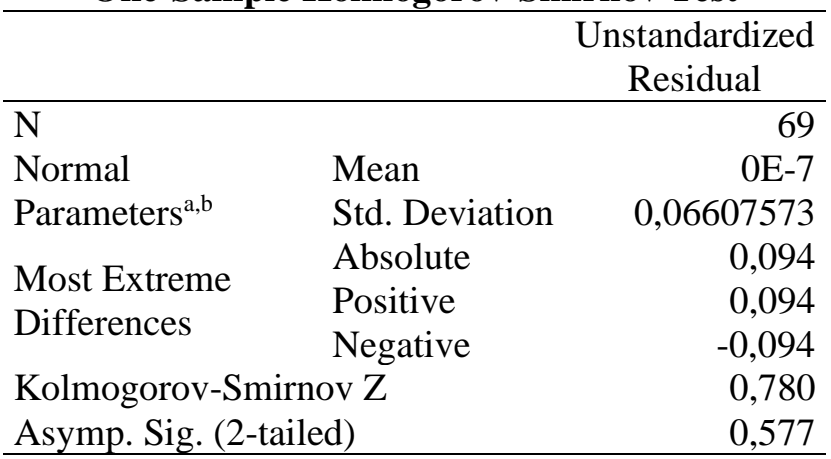

a. Test distribution is Normal.

b. Calculated from data.

Pada uji normalitas Kolmogorov Smirnov data residual dikatakan berdistribusi normal apabila nilai signifikan di atas 0,05. Berdasarkan Tabel 3.2. diatas, diperoleh keputusan bahwa nilai Asym.Sig(2-tailed) adalah sebesar 0,577 atau lebih besar dari 0,05. Maka dapat disimpulkan bahwa data penelitian berdistribusi normal.

\section{b. Uji Heterokedastisitas}

Dalam penelitian ini untuk uji heterokedasitas memakai scatterplot. Berikut ini gambar grafik hasil uji heteroskedastisitas pada gambar berikut: 


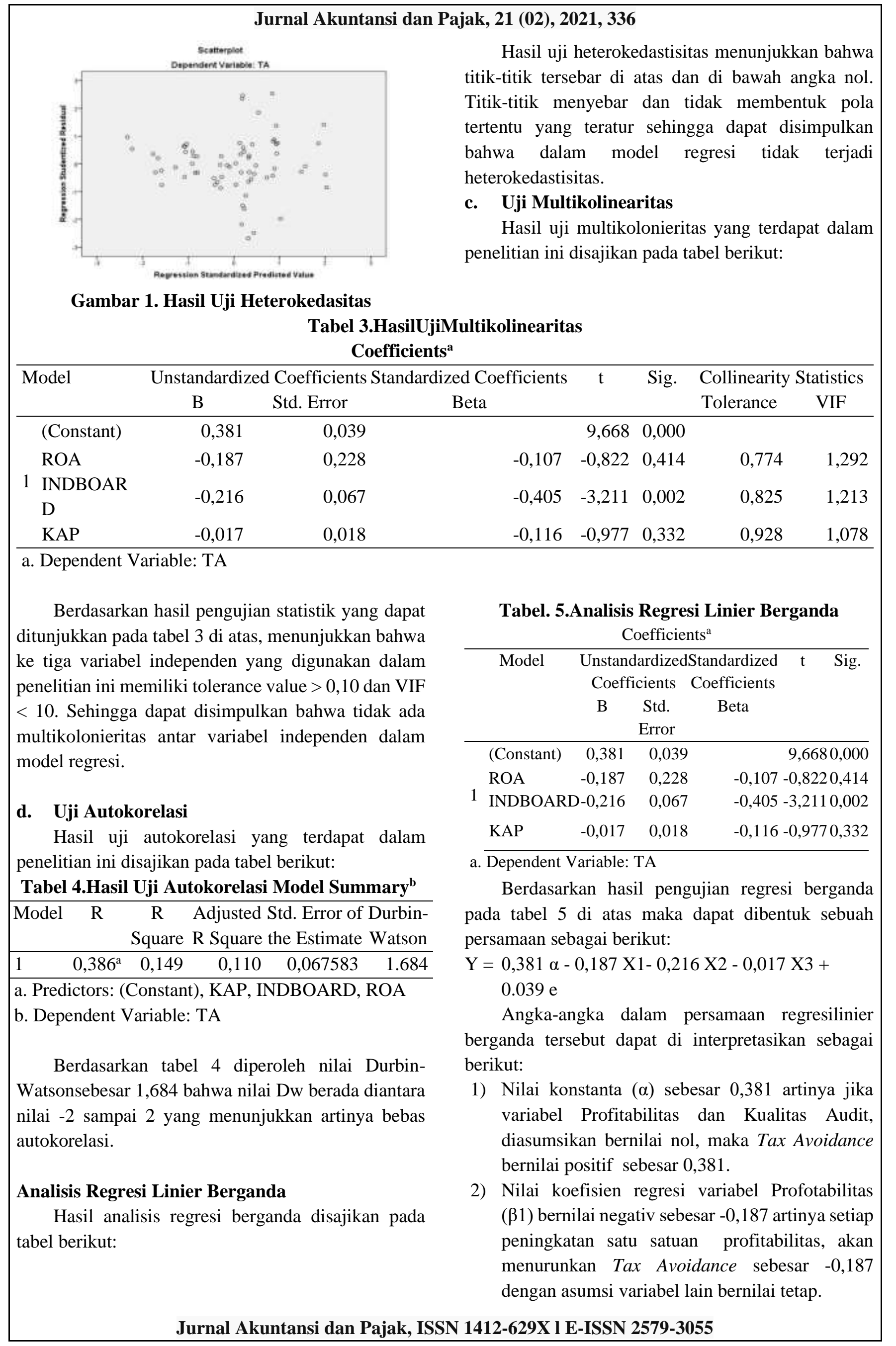


3) Nilai koefisien regresi variabel Profotabilitas $(\beta 1)$ bernilai negative sebesar $-0,187$ artinya setiap peningkatan satu satuan profitabilitas, akan menurunkan Tax Avoidance sebesar -0,187 dengan asumsi variabel lain bernilai tetap.

\section{Uji Koefisien Determinasi (R2)}

Hasil uji koefisen determinasi penelitian ini sebagai berikut:

Tabel 6.Hasil Uji Koefisien Determinasi $\left(\mathbf{R}^{2}\right)$ Model Summary ${ }^{b}$

\begin{tabular}{llll}
\hline Model & R & R Square Adjusted R Std. Error of
\end{tabular} Square the Estimate

\begin{tabular}{lllll}
\hline 1 & $0,386^{\mathrm{a}}$ & 0,149 & 0,110 & 0,0675 \\
\hline
\end{tabular}

a. Predictors: (Constant), KAP, INDBOARD, ROA

b. Dependent Variable: TA

Dapat dilihat dari tabel 6 di atas menunjukkan bahwa koefisien determinasi yang menunjukkan nilai adjusted R2 sebesar 0,110. Hal ini menunjukkan bahwa variabel terikat Tax Avoidance dapat dijelaskan oleh variabel bebas yaitu profitabilitas, komisaris independen dan kualitas audit sebesar $11 \%$. Sedangkan $89 \%$ variabel Tax Avoidance dapat dijelaskan oleh variabel lain di luar model yang diteliti.

\section{Uji Hipotesis}

a. Uji t

Hasil uji statistik t disajikan dalam tabel di bawah ini:

Tabel 7. Hasil Uji Statistik t

\begin{tabular}{|c|c|c|c|c|c|}
\hline \multicolumn{6}{|c|}{ Coefficients ${ }^{\mathrm{a}}$} \\
\hline \multirow{3}{*}{ Model } & \multicolumn{5}{|c|}{ Unstandardized Standardized } \\
\hline & \multicolumn{2}{|c|}{ Coefficients } & \multirow{2}{*}{$\begin{array}{c}\text { Coefficients } \\
\text { Beta }\end{array}$} & \multirow{2}{*}{$\mathrm{T}$} & \multirow{2}{*}{ Sig. } \\
\hline & B & $\begin{array}{l}\text { Std. } \\
\text { Error }\end{array}$ & & & \\
\hline (Constant) & 0,381 & 0,039 & & 9,66 & 0,000 \\
\hline $1 \quad \mathrm{ROA}$ & $-0,187$ & 0,228 & $-0,107$ & $-0,82$ & 0,414 \\
\hline INDBOARD & $-0,216$ & 0,067 & $-0,405$ & $-3,21$ & \\
\hline KAP & $-0,017$ & 0,018 & $-0,116$ & $-0,97$ & 0,332 \\
\hline
\end{tabular}

a. Dependent Variable: TA

Sumber: data sekunder yang diolah(2020)

Berdasarkan tabel 7. di atas dapat diartikan bahwa variabel Profitabilitas (ROA) mempunyai arah koefisien negatif $-0,187$ dengan tingkat signifikansi sebesar 0,414 lebih besar dari 0,05 dengan t-statistik sebesar -0,882 dan t-tabel sebesar 1,992, yang berarti t-hitung < t-tabel. Hal tersebut menunjukkan bahwa variabel profitabilitas tidak berpengaruh signifikan terhadap Tax Avoidance. Hasil penelitian ini sejalan dengan penelitian yang menyatakan ROA tidak berpengaruh terhadap tax avoidance pada perusahaan yang terdaftar di JII tahun 2011-2015 (Ismi \& Linda, 2016). Dan bertentangan dengan penelitian yang menyatakan ROA berpengaruh pada penghindaran pajak pada perusahaan yang terdaftar di BEI dan masuk peringkat CGPI periode 20102012 (Darmawan \& Sukartha, 2014).

Variabel komisaris independen (INDBOARD) memiliki arah koefisien negatif -0,216 dengan tingkat signifikansi sebesar 0,002 lebih kecil dari 0,05 dengan t-statistik sebesar $-3,211$ dan t-tabel sebesar 1,992, yang berarti t-hitung < t- tabel. Hal tersebut menunjukkan bahwa variabel komisaris independen berpengaruh signifikan terhadap Tax Avoidance namun dengan nilai koefisien negatif. Hasil penelitian ini sejalan dengan penelitian yang menyatakan pengujian hipotesis bahwa variabel komisaris independen berpengaruh terhadap penghindaran pajak (Tax Avoidance) Studi Empiris Pada Sektor Industri Barang Konsumsi yang terdaftar di Bursa Efek Indonesia Periode 2010-2014 (Eksandy, 2017). Dan penelitian lain yang menyatakan Dewan komisaris independen berpengaruh positif terhadap Tax Avoidance pada perusahaan perbankan yang terdaftar di BEI periode 2012 - 2016 (Dewi, 2019).

Variabel Kualitas Audit (KAP) memiliki arah koefisien negative -0,017 dengan tingkat signifikansi sebesar 0,332 lebih besar dari 0,05 dengan t-statistik sebesar -0,977 dan t-tabel sebesar 1,992, yang berarti thitung < t-tabel. Hasil penelitian ini sejalan dengan penelitian yang menunjukkan bahwa variabel kualitas audit tidak berpengaruh terhadap Tax Avoidance. memiliki hasil penelitian bahwa kualitas audit tidak berpengaruh terhadap Tax Avoidance(Damayanti \& Susanto, 2016).

b. Uji F

Hasil uji kebaikan model (uji statistik F) disajikan dalam tabel ANOVA di bawah ini:

Tabel 8. Hasil Uji Signifikansi (Uji Statistik F)

\begin{tabular}{|c|c|c|c|c|c|}
\hline \multirow[b]{2}{*}{ Model } & \multicolumn{3}{|c|}{ ANOVA $^{\mathrm{a}}$} & \multirow[b]{2}{*}{$\mathrm{F}$} & \multirow[b]{2}{*}{ Sig. } \\
\hline & $\begin{array}{l}\text { Sum of } \\
\text { Squares }\end{array}$ & df & $\begin{array}{l}\text { Mean } \\
\text { Square }\end{array}$ & & \\
\hline Regression & 0,052 & 3 & 0,017 & 3,791 & $0,014^{\mathrm{b}}$ \\
\hline 1 Residual & 0,297 & 65 & 0,005 & & \\
\hline Total & 0,349 & 68 & & & \\
\hline
\end{tabular}

a. Dependent Variable: TA

b. Predictors: (Constant), KAP, INDBOARD, ROA

Berdasarkan tabel 3.8. di atas, diketahui nilai $\mathrm{F}$ hitung sebesar 3,791 dan nilai signifikansi sebesar 0,014 . Jika nilai signifikansi $(0,014)<$ alpha $(0,05)$, maka dapat disimpulkan kombinasi variabel bebas yang terdiri dari profitabilitas, komisaris independen dan kualitas audit secara bersama-sama mempengaruhi Tax Avoidance. 


\subsection{Pembahasan}

\section{a. Pengaruh Profitabilitas TerhadapTax Avoidance.}

Berdasarkan uji hipotesis secara parsial didapa tprofitabilitas tidak berpengaruh signifikan terhadap Tax Avoidance. Hasil penelitian ini sejalan dengan penelitian yang menyatakan ROA tidak berpengaruh terhadap tax avoidance pada perusahaan SektorIndustriDasardan Kimia yang terdaftar di BEI(Permata et al., 2018). Dan bertentangan dengan penelitian yang menyatakan ROA berpengaruh pada penghindaran pajak (Fadila et al., 2017; Gede Hendy Darmawan Made Sukartha, 2014; Handayani, 2017; Luh et al., 2017).

\section{b. Pengaruh Komisaris Independen Terhadap Tax Avoidance.}

Hasil uji hipotesis menunjukkan bahwa variabel komisaris independen berpengaruh signifikan terhadap Tax Avoidance namun dengan nilai koefisien negatif. Hasil penelitian ini sejalan dengan penelitian yang menyatakan pengujian hipotesis bahwa variabel komisaris independen berpengaruh terhadap penghindaran pajak (Tax Avoidance) Studi Empiris Pada Sektor Industri Barang Konsumsi yang terdaftar di Bursa Efek Indonesia Periode 2010-2014 (Eksandy, 2017). Dan penelitian lain yang menyatakan Dewan komisaris independen berpengaruh positif terhadap Tax Avoidance pada perusahaan perbankan yang terdaftar di BEI periode 2012 - 2016 (Dewi, 2019).

\section{c. Pengaruh Kualitas Audit TerhadapTax Avoidance.}

Hasil uji hipotesis penelitian ini sejalan dengan penelitian yang menunjukkan bahwa variabel kualitas audit tidak berpengaruh terhadap Tax Avoidance. memiliki hasil penelitian bahwa kualitas audit tidak berpengaruh terhadap Tax Avoidance(Damayanti \& Susanto, 2016).

\section{KESIMPULAN}

Berdasarkan hasil analisis data dan pembahasan yang telah dikemukakan pada bab sebelumnya, dapat ditarik kesimpulan bahwa berdasarkan hasil pengujian hipotesis menunjukkan sebagai berikut :

a. Profitabilitas (ROA) tidak berpengaruh signifikan terhadap Tax Avoidance. Memiliki nilai t-hitung sebesar -0,882 dan t-tabel sebesar 1,992, yang berarti t-hitung < t-tabel dengan tingkat signifikansi sebesar 0,414 lebih besar dari 0,05. Hal ini menunjukkan bahwa variabel profitabilitas tidak berpengaruh signifikan terhadap Tax Avoidance.

b. Komisaris independen (INDBOARD) berpengaruh signifikan terhadap Tax Avoidance namun dengan nilai koefisien negatif. Memiliki nilai t-hitung yang lebih kecil dari nilai t-tabel ($3,211<1,992)$ dan taraf signifikansi yang lebih kecil dari $0,05(0,002<0,05)$. Hal ini menunjukkan bahwa variabel Komisaris Independen berpengaruh signifikan terhadap Tax Avoidance.

c. Kualitas Audit (KAP) tidak berpengaruh signifikan terhadap Tax Avoidance. Memiliki nilai t-hitung sebesar -0,977 dan t-tabel sebesar 1,992, yang berarti t-hitung < t-tabel dengan tingkat signifikansi sebesar 0,332 lebih besar dari 0,05. Hal ini menunjukkan bahwa variabel kualitas audit tidak berpengaruh signifikan terhadap Tax Avoidance.

d. Profitabilitas (ROA), Komisaris Independen (INDBOARD), dan Kualitas Audit (KAP) berpengaruh signifikan terhadap Tax Avoidance. Memiliki nilai F-hitung sebesar 3,791 > F-tabel sebesar 3,12 dan nilai signifikansi 0,014 kurang dari alpha 0,05. Hal ini menunjukkan bahwa adanya pengaruh yang simultan antara Profitabilitas (ROA).

Berdasarkan kesimpulan dalam penelitian ini, saran yang diberikan untuk penelitian yang akan datang antara lain :

a. Bagi perusahaan BUMN sebaiknya agar lebih berhati-hati dalam mengambil keputusan yang terkait dengan perencanaan pajak terutama mengenai Tax Avoidance yang dilakukan agar terhindar dari sanksi administrasi pajak dan kesalahpahaman investor sehingga membentuk persepsi yang buruk kepada perusahaan.

b. Bagi investor sebaiknya dalam pengambilan keputusan investasi untuk mengkaji terlebih dahaulu bagaimana kinerja suatu perusahaan dan tetap mematuhi peraturan tentang perpajakan, penghindaran pajak bukan hal yang wajar tetapi selalu dilakukan. Tax Avoidance akan memberikan dampak yang kurang baik untuk kedua belah pihak yang bersangkutan baik dari pihak investor, perusahaan maupun pemerintah.

c. Bagi peneliti selanjutnya disarankan untuk mengembangkan variabel independen yang digunakan, menggunakan metode pengukuran Corporate Governance selain proporsi komisaris 


\section{Jurnal Akuntansi dan Pajak, 21 (02), 2021, 339}

independen, dan penelitian selanjutnya dapat dilakukan dengan menggunakan sektor industri lain seperti industri keuangan, jasa, atau perbankan.

\section{UCAPAN TERIMA KASIH}

Terimakasih kepada Sekretaris Prodi Manajemen yang memungkinkan terselesaikannya artikel ini dan keluarga besar STIE Banten yang memberi support.

\section{REFERENSI}

Damayanti, F., \& Susanto, T. (2016). Pengaruh Komite Audit, Kualitas Audit, Kepemilikan Institusional, Risiko Perusahaan dan Return On Assets terhadap Tax Avoidance. ESENSI, 5(2), 187-206. https://doi.org/10.15408/ess.v5i2.2341

Darmawan, I., \& Sukartha, I. (2014). Pengaruh Penerapan Corporate Governance, Leverage, Roa, Dan Ukuran Perusahaan Pada Penghindaran Pajak. E-Jurnal Akuntansi, 9(1), 143-161.

Dewi, N. M. (2019). Pengaruh Kepemilikan Institusional, Dewan Komisaris Independen dan Komite Audit Terhadap Penghindaran Pajak (Tax Avoidance) Pada Perusahaan Perbankan Yang Terdaftar Di Bursa Efek Indonesia Periode 20122016. Jurnal Akuntansi Dan Keuangan, 9(2), 171-189.

Eksandy, A. (2017). Pengaruh Komisaris Independen, Komite Audit, dan Kualitas Audit terhadap Penghindaran Pajak (Tax Avoidance) (Studi Empiris Pada Sektor Industri Barang Konsumsi yang terdaftar di Bursa Efek Indonesia Periode 2010-2014). Competitive Jurnal Akuntansi Dan Keuangan, $\quad 1(1), \quad 1$. https://doi.org/10.31000/competitive.v1i1.96

Fadila, M., Rasuli, M., \& Rusli, R. (2017). Pengaruh Return on Asset, Leverage, Ukuran Perusahaan Kompensasi Rugi Fiskal, Kepemilikan Institusional, Dan Koneksi Politik Terhadap Penghindaran Pajak. https://www.neliti.com/publications/130249/pen garuh-return-on-asset-leverage-ukuranperusahaan-kompensasi-rugi-fiskal-kepem

fiskal.kemenkeu.go.id. (2015). Kerangka Ekonomi Makro dan Pokok-Pokok Kebijakan Fiskal Tahun 2016. https://fiskal.kemenkeu.go.id/data/document/ke m/2016/files/kem_ppkf_2016.pdf
Gede Hendy Darmawan Made Sukartha, I. I. (2014). Pengaruh Penerapan Corporate Governance, Leverage, Return On Assets dan Ukuran Perusahaan pada Penghindaran Pajak. E-Jurnal Akuntansi Universitas Udayana, 9(1), 143-161. https://ojs.unud.ac.id/index.php/Akuntansi/articl e/download/8635/7643

Handayani, R. (2017). Pengaruh Return on Assets (ROA), Leverage dan Ukuran Perusahaan Terhadap Tax Avoidance Pada Perusahaan Perbankan yang Listing di BEI Periode Tahun. Jurnal Akuntansi Maranatha, 10(1), 72-84. https://journal.maranatha.edu/index.php/jam/arti cle/view/930

Ismi, F., \& Linda. (2016). Pengaruh Thin Capitalization, Return On Asset, Dan Corporate Governance Pada Perusahaan Jakarta Islami Index ( JII ). Jurnal Ilmiah Mahasiswa Ekonomi Akuntansi, 1(1), 150-165.

Khairunisa, K., Hapsari, D. W., \& Aminah, W. (2017). Kualitas Audit, Corporate Social Responsibility, Dan Ukuran Perusahaan Terhadap Tax Avoidance. Jurnal Riset Akuntansi Kontemporer, 9(1), 39-46. https://doi.org/10.23969/jrak.v9i1.366

Luh, N., Dewi, P. P., \& Noviari, N. (2017). Pengaruh ukuran perusahaan, leverage, profitabilitas dan corporate social responsibility terhadap penghindaran pajak (Tax Avoidance). In ojs.unud.ac.id (Vol. 21). www.kompas.com.

Minanari. (2018). Pengaruh Profitabilitas, Manajemen Laba dan Kebijakan Dividen terhadap Nilai Perusahaan (Studi Empiris pada Perusahaan Manufaktur yang Terdaftar di BEI Periode 20152016). Profita, 1(11), 139-149.

Permata, A. D., Nurlaela, S., \& Wahyuningsih, E. M. (2018). Pengaruh Size, Age, Profitability, Leverage dan Sales Growth Terhadap Tax Avoidance. Jurnal Akuntansi Dan Pajak, 19(1), 10. https://doi.org/10.29040/jap.v19i1.171

Sari, G. M. (2014). Pengaruh Corporate Governance , Ukuran Perusahaan, Kompensasi Rugi Fiskal dan Struktur Kepemilikan terhadap Tax Avoidance (Studi Empiris Pada Perusahaan Manufaktur yang Terdaftar di BEI). c, 1-43. https://doi.org/10.16526/j.cnki.114762/tp.2014.11.051

Sartori, N. (2011). Effects of Strategic Tax Behaviors on Corporate Governance . SSRN Electronic Journal. https://doi.org/10.2139/ssrn.1358930 